\title{
Eficiência do modelo Ceres-Maize na simulação do desempenho de híbridos de milho ${ }^{1}$
}

\author{
Antonio Marcos de Andrade Rezende Pereira ${ }^{2}$, Renzo Garcia Von Pinho ${ }^{3}$, Carlos Maurício Paglis ${ }^{3}$, José Luiz de
} Andrade Rezende Pereira ${ }^{2}$, Tomaz Falqueto Altoé ${ }^{4}$

\section{RESUMO}

O modelo Ceres-Maize foi desenvolvido para simulação do desenvolvimento e desempenho da cultura do milho e tem sido utilizado como ferramenta de auxílio no planejamento das safras e tomadas de decisões pelos agricultores de diversos países. Com o objetivo de avaliar a eficiência do modelo Ceres-Maize na simulação do desempenho de híbridos de milho nas condições tropicais, foi conduzido um experimento utilizando cinco híbridos (AG7000, AG8060, DKB199, GNZ2004 e P30F90) avaliados em três épocas de semeadura (24/11/2006, 19/12/2006 e 13/01/2007) na Universidade Federal de Lavras, Lavras, MG. O delineamento foi o DBC com três repetições. Avaliaram-se datas de florescimento e maturidade fisiológica, número de grãos por metro quadrado, massa de grãos e produtividade de grãos, que foram comparados com os dados simulados pelo quadrado médio do erro (RSME), porcentagem de desvio (PD) e índice de concordância (d). Os resultados indicaram que o milho semeado em janeiro apresentou menores valores de número de grãos por metro quadrado, massa de grão e produtividade de grãos do que semeaduras em novembro e dezembro. $\mathrm{O}$ Ceres-Maize mostrou-se muito eficiente para simular as datas de florescimento e de maturidade fisiológica em razão dos valores de RSME terem sido inferiores a 10\%, os de 'd’ superiores a 0,80 e o maior valor de PD -11\%. Para o número de grãos por metro quadrado, massa de grãos e produtividade de grãos, a simulação foi considerada boa com valores de RSME inferiores a 20\%. Para essas variáveis foram observados maiores valores de PD, principalmente na última época de semeadura, evidenciando que condições ambientais não favoráveis ao bom desempenho da cultura afetam a eficiência da simulação. O modelo Ceres-Maize mostrou ser boa ferramenta de simulação das características agronômicas de híbridos de milho.

Palavras-chave: Zea mays, modelagem, produtividade

\section{ABSTRACT}

\section{Efficiency of the ceres-maize model in the simulation of corn hybrid performance}

The CERES-Maize model was developed for simulating the development and performance of corn and has been used as a tool for planning and decision making by farmers in several countries. The objective of this study was to evaluate the efficiency of the CERES-Maize model in the simulation of agronomic characteristics of corn hybrids on tropical conditions. A field experiment was conducted with five hybrids (AG7000, AG8060, DKB199, GNZ2004 and P30F90) and three sowing times (24/11/2006, 19/12/2006 and 13/01/2007) in an experimental area of the Agriculture Department of the Federal University of Lavras, Lavras, Minas Gerais State, Brazil. The treatments were arranged in a randomized block design with three replicates. Data were collected on flowering dates and physiological maturity,

\footnotetext{
Recebido para publicação em abril de 2008 e aprovado em junho de 2010

${ }^{1}$ Parte do trabalho de dissertação de mestrado do primeiro autor.

${ }^{2}$ Engenheiro Agrônomo, Mestre. Departamento de Agricultura da Universidade Federal de Lavras-UFLA, 37200-000, Caixa postal 3037, Lavras, Minas Gerais, Brasil. antoniomarcosandrade@yahoo.com.br

${ }^{3}$ Engenheiro Agrônomo, Doutor. Departamento de Agricultura da Universidade Federal de Lavras-UFLA, 37200-000, Caixa postal 3037, Lavras, Minas Gerais, Brasil. renzo@ufla.br ${ }^{4}$ Engenheiro agrônomo. Rua Capitão Francisco Ribeiro, 280, ap. 101, 37200-000, Lavras, Minas Gerais, Brasil. tfaltoe@yahoo.com.br
}

Rev. Ceres, Viçosa, v. 57, n.4, p. 486-493, jul/ago, 2010 
grain number per square meter, grain mass and grain yields. These data were compared with the data simulated by the model using the mean square error (RSME), percentage deviation (PD) and agreement index (d). The results showed that corn sown in January, independent of the hybrid, had lower grain number per square meter, grain mass and grain yield than sowings in November and December. CERES-Maize proved very efficient to simulate the flowering and physiological maturity dates as the RSME values were below $10 \%$, the 'd'values were above 0.80 , and the highest PD value was $-11 \%$. For grain number per square meter, grain mass and grain yield, the simulation was considered good, with RSME below 20\%. These variables had the highest PD values, mainly in the last sowing date, indicating that environmental conditions unfavorable to the good performance of the crop affect efficiency of simulation. The CeresMaize model was proven a good tool for simulation of agronomic characteristics in corn hybrids.

Key words: Modelling, Zea mays, yield.

\section{INTRODUÇÃO}

A composição química, o valor nutritivo e o potencial produtivo tornam o milho um dos mais importantes cereais cultivados e consumidos no mundo. Apesar disso, apenas uma pequena parcela de agricultores consegue explorar ao máximo o potencial produtivo da cultura, em virtude da ausência de recursos naturais que condicionam elevados desempenhos. Entre esses, consideram-se os de maior destaque o clima, manejo de nutrientes, potencial genético e manejo de pragas e doenças (Hoeft, 2003).

A cultura do milho pode apresentar alta variabilidade temporal da produtividade de grãos, causada principalmente por variações nos elementos climáticos (Bergonci et al., 2001). Aumento da produtividade de milho no Brasil poderia ser obtido pela otimização das áreas produtivas por meio de manejo eficiente da variabilidade espacial dos atributos de solo, clima e manejo, podendo os modelos de simulação auxiliarem nesse planejamento (Hurtado, 2004).

Um modelo de crescimento e desenvolvimento de plantas visa, entre outras finalidades, buscar informações básicas das diversas interações entre a planta e o ambiente, maximizando o uso de recursos naturais de cada região, ou de determinada condição de cultivo. Sendo assim, podese definir a melhor forma de manejo de uma cultura e ainda favorecer o planejamento das atividades agrícolas e da pesquisa científica. Pesquisadores de diversas partes do mundo vêm usando vários modelos de culturas, testando a habilidade na simulação de eventos fenológicos, produção de biomassa e produtividade de grãos (Dourado Neto et al., 2001).

Entre as vantagens de uso dos modelos de simulação, encontra-se a possibilidade de economizar tempo, esforço e recursos necessários para a tomada de decisões relacionadas ao manejo das culturas. De maneira similar, experimentos de campo detalhados e de longa dura- ção podem ser melhor definidos, quando os modelos proporcionam alcances iniciais nas respostas esperadas (Jame \& Curtfourth, 1996).

Entre os modelos desenvolvidos para simulação do crescimento de plantas, particularmente para gramíneas, destacam-se os modelos Ceres, sendo denominados Ceres-Maize, o que se destina para simulações com a cultura do milho (Jones \& Kiniry, 1986). A principal inovação desse modelo é o uso do conceito de coeficiente genético, o qual significa que uma característica comum a todas as variedades de milho pode variar quantitativamente, explicando as diferentes adaptações (Salvador, 1993).

O objetivo deste estudo foi avaliar a eficiência do modelo Ceres-Maize na simulação de datas de florescimento e maturidade fisiológica, componentes da produção e produtividade de grãos de híbridos de milho em três épocas de cultivo na região de Lavras-MG.

\section{MATERIAL E MÉTODOS}

O experimento foi conduzido na safra agrícola 2006/ 2007, em Lavras-MG, em Latossolo Vermelho Escuro (EMBRAPA, 2000), em área do Departamento de Agricultura da Universidade Federal de Lavras, situada na latitude $21^{\circ} 20^{\prime}$ Sul, longitude $45^{\circ} 00^{\prime \prime}$ Oeste, a $822 \mathrm{~m}$ de altitude, com temperatura média de $19,4{ }^{\circ} \mathrm{C}$ e precipitação anual de 1,529 mm. As características químicas do solo por ocasião da semeadura do milho eram: $\mathrm{pH}\left(\mathrm{H}_{2} \mathrm{O}\right)=$ 5,8; $\mathrm{P}=10 \mathrm{mg} \mathrm{dm}^{-3}$ (Mehlich I); $\mathrm{K}=84 \mathrm{mg} \mathrm{dm}^{-3} ; \mathrm{Ca}=1,9$ $\mathrm{cmol}_{\mathrm{c}} \mathrm{dm}^{-3} ; \mathrm{Mg}=1,1 \mathrm{cmol} \mathrm{dm}_{\mathrm{c}}^{-3} ; \mathrm{Al}=0,0 \mathrm{cmol}_{\mathrm{c}} \mathrm{dm}^{-3} ; \mathrm{H}+\mathrm{Al}$ $=2,6 \mathrm{cmol}_{\mathrm{c}} \mathrm{dm}^{-3} ; \mathrm{S} \cdot \mathrm{B}=3,2 \mathrm{cmol}_{\mathrm{c}} \mathrm{dm}^{-3} ; \mathrm{T}=5,8 \mathrm{cmol}_{\mathrm{c}} \mathrm{dm}^{-3}$; $\mathrm{V}=55,2 \%$; e $\mathrm{MO}=2,7 \mathrm{dag} \mathrm{kg}^{-1}$.

Foi utilizado o delineamento estatístico blocos casualizados, com quinze tratamentos, três repetições e parcelas de quatro linhas com $10 \mathrm{~m}$ de comprimento e 80 $\mathrm{cm}$ entre linhas $\left(32 \mathrm{~m}^{2}\right)$. Os tratamentos foram constituí- 
dos de três épocas de semeadura (24 de novembro de 2006, 19 de dezembro de 2006 e 13 de janeiro de 2007) e de cinco híbridos de milho (AG7000, AG8060, DKB199, GNZ2004 e P30F90). A área experimental encontrava-se em pousio desde março de 2006 e coberta com espécies daninhas que foram roçadas e dessecadas com o herbicida Rondup ${ }^{\circledR}$ na dose 3,0 1 ha $^{-1}$. A semeadura foi realizada manualmente e o estande definido após o desbaste, quando as plantas se encontravam com três a quatro folhas totalmente expandidas, objetivando-se uma população de 60000 plantas ha-1. Foi realizada adubação de base na dose $350 \mathrm{~kg} \mathrm{ha}^{-1}$ do adubo formulado 8-28-16 e adubação de cobertura quando as plantas encontravam-se com cinco folhas na dose de $350 \mathrm{~kg} \mathrm{ha}^{-1}$ do adubo 30-00-20. Para controle de plantas daninhas, 15 dias após a emergência das plantas foi aplicado o herbicida Atrazina na dose de 4,0 1 ha $^{-1}$. Para o controle preventivo de pragas foi realizada uma pulverização com inseticida Decis na dose de $200 \mathrm{~mL} \mathrm{ha}^{-1}$.

\section{Características avaliadas}

O florescimento feminino foi registrado quando os estigmas estavam visíveis na espiga em $50 \%$ das plantas de cada parcela e com posterior cálculo dos graus-dia por meio da soma térmica dos valores diários da diferença entre a temperatura média diária e a temperatura base durante o período da emergência das plantas e florescimento feminino (Soler, 2004).

A maturidade fisiológica foi determinada regularmente amostrando-se duas espigas por parcela para se identificar a presença da camada negra na base dos grãos, sendo calculado os graus-dia pela soma térmica dos valores da diferença entre a temperatura média diária e a temperatura-base durante o período entre a emergência e a maturidade fisiológica (Soler, 2004).

A colheita foi realizada manualmente em cinco metros lineares no centro das duas fileiras úteis das parcelas. $\mathrm{O}$ número de grãos por $\mathrm{m}^{2}$ foi obtido pela contagem dos grãos de cinco plantas por repetição e mutiplicando a média dessas pelo estande referente à parcela. A massa de grão (MG) foi obtida da média da massa de cinco grupos de 100 grãos por parcela. A produção de grãos das parcelas foi transformada para $\mathrm{kg} \mathrm{ha}^{-1}$.

Os dados foram submetidos à análise de variância, empregando-se o sistema de análise estatística SISVAR, versão 4.0 (Ferreira, 2000), e as médias dos tratamentos agrupadas pelo teste de Tukey a 5\% de probabilidade.

\section{Teste do modelo ceres-maize}

Dentre os parâmetros de entrada do modelo necessários para a simulação, os climáticos foram determinados com dados diários referentes às temperaturas máxima e mínima $\left({ }^{\circ} \mathrm{C}\right)$, precipitação $\left(\mathrm{mm}\right.$ dia $\left.{ }^{-1}\right)$ e radiação solar $(\mathrm{Mj}$ $\mathrm{m}^{-2}$ dia $^{-1}$ ), obtidos de uma estação meteorológica localizada a 500 m da área experimental, nas épocas correspondentes ao período de condução do experimento. As informações de solo foram obtidas no estudo realizado por Hurtado (2004) e complementadas com a análise química de solo.

Na obtenção dos parâmetros de manejo, foram determinadas: a população de plantas (plantas $\mathrm{m}^{-2}$ ), data e profundidade de semeadura (m), as adubações e a latitude do local.

Os parâmetros do modelo referentes ao comportamento dos híbridos utilizados foram: graus-dia entre a emergência das plantas e o final do estádio juvenil (P1), coeficiente de sensitividade ao fotoperíodo (P2), graus-dia entre o florescimento e a maturidade fisiológica (P5), número potencial de grãos por planta (G2) e taxa potencial de crescimento de grãos (G3).

O modelo Ceres-Maize foi calibrado e testado para as condições experimentais deste estudo, conforme recomendações de Hoogenboom et al. (2003). Na calibração do modelo foram utilizados os dados das parcelas instaladas no mês de novembro de 2006, e os coletados nas parcelas instaladas em dezembro de 2006 e janeiro 2007 foram empregados como dados independentes para a avaliação.

Na calibração, o parâmetro P2 foi mantido igual a 0,5 para os cinco híbridos, valor típico para híbridos tropicais (Jones \& Kiniry, 1986).

O valor do P1 foi ajustado até as datas estimadas de florescimento aproximarem-se das observadas. Com o novo valor de P1 constante, ajustou-se P5 até as datas estimadas e observadas dos graus-dia entre o florescimento e a maturidade fisiológica (PMF) aproximaremse. No ajuste de G2 foram acrescentados 10 grãos por vez. Finalmente, foi alterado o valor de G3 a cada 0,01 mg grãos ${ }^{-1}$ dia $^{-1}$ até o rendimento simulado ficar o mais próximo do observado (Lima, 1995).

Os dados verificados e simulados de datas de florescimento e maturidade fisiológica, número de grãos por metro quadrado, massa de grão e produtividade de grãos foram comparados utilizando-se o índice “d” de concordância (Willmott et al., 1985), o qual é definido como:

$d=1-\left[\frac{\sum_{i=1}^{N}(P i-O i)^{2}}{\sum_{i=1}^{N}\left(P^{\prime} i|+| O^{\prime} i \mid\right)^{2}}\right]$

em que $\mathrm{N}$ é o número de observações, Pi é o valor simulado, Oi é o valor observado, P’i = Pi - M e O’i = Oi $\mathrm{M}$, sendo $\mathrm{M}$ a média da variável observada.

De acordo com o índice estatístico d, quanto mais próximo da unidade melhor a concordância entre as variáveis simuladas e observadas. 
A porcentagem de desvio (PD) foi calculada considerando-se a diferença entre os valores simulados e observados, dividido pelos valores observados e multiplicando por 100. Porcentagem de desvios negativos indica subestimativa, enquanto porcentagem de desvios positivas indica superestimativa.

O quadrado médio do erro (RMSE) foi calculado de acordo com Loague \& Green (1991), utilizando-se a seguinte equação:

$\operatorname{RMSE}=\sqrt{\frac{\sum_{\mathrm{i}=1}^{\mathrm{N}}(\mathrm{Pi}-\mathrm{Oi})^{2}}{\mathrm{~N}}} * \frac{100}{\mathrm{M}}$

em que Pi e Oi referem-se às variáveis estudadas simuladas e observadas, respectivamente.

O RMSE indica a diferença relativa, em \%, entre os valores simulados e observados. A simulação é considerada excelente quando RMSE é menor do que $10 \%$, boa entre 10 e $20 \%$, aceitável entre 20 e $30 \%$ e pobre quando maior do que 30\% (Jamieson et al., 1991).

\section{RESULTADOS E DISCUSSÃO}

Na análise de variância $(\mathrm{F}<0,05)$ constatou-se que todas as características avaliadas foram influenciadas apenas pelo fator épocas de semeadura, sendo não- significativos os efeitos de híbridos e da interação entre híbridos e épocas.

Comparando as três épocas de semeadura, observase que número de grãos por metro quadrado, massa de grãos e produtividade de grãos foram semelhantes na primeira e segunda épocas de semeadura, ocorrendo na última época acentuada redução na produtividade de grãos e de todos os componentes do rendimento (Tabela 1).

De acordo com Fancelli \& Dourado Neto (2000), observa-se que a precipitação no período de condução do experimento foi suficiente para o desenvolvimento da cultura nas três épocas de plantio, no entanto mal distribuída, principalmente no plantio de janeiro, no qual durante o período entre o florescimento e a maturidade fisiológica foram registrados apenas $46 \mathrm{~mm}$ de precipitação (Figura 1). Fancelli \& Dourado Neto (2000) relatam que a ocorrência de deficiência hídrica de uma semana durante o florescimento masculino pode implicar em redução de produção em torno de 50\%, enquanto após a polinização, nas mesmas condições, as perdas podem chegar a $25 \%$.

Com os parâmetros calibrados o modelo Ceres-Maize simula o desenvolvimento e a produtividade do milho (Tabela 2).

O número de dias observados desde a semeadura até o florescimento feminino para os cinco híbridos nas três épocas de semeadura e os valores simulados para essa fase com o modelo Ceres-Maize foram similares em magnitude (Tabela 3).

Pode se observar que os valores verificados e simulados de dias desde a semeadura até o florescimento feminino foram muito semelhantes, com desvios percentuais (PD) variando de -4.3 a 1,6. O índice de concordância "d" foi elevado, variando de 0,82 a 0,93 , e o RMSE expresso em porcentagem foi menor ou igual a 2,7, mostrando a robustez do modelo Ceres-Maize em simular a data de florescimento nos cinco híbridos nas três épocas de semeadura. Resultados semelhantes foram encontrados por Hurtado (2004), que, ao avaliar a eficiência do modelo Ceres-Maize na simulação de data de florescimento para o híbrido A2345, na mesma região, obteve valores muito próximos para dados simulados e observados com PD inferior a $5 \%$.

O período desde a semeadura até a maturidade fisiológica foi simulado pelo modelo Ceres-Maize com precisão nos cinco híbridos com valores de RMSE menores e igual a 6,8\% (Tabela 4).

O índice de concordância "d" variou entre 0,80 e 0,99 e os desvios percentuais (PD) de -11,3 a 2,5. Observou-se tendência do modelo subestimar esse período para todos os híbridos na última época de semeadura.

A simulação para o número de grãos (grãos $\mathrm{m}^{-2}$ ) foi considerada boa para todos os híbridos com os valores de RSME abaixo de 20\% (Tabela 5). No entanto, os híbridos AG8060 e DKB199 apresentaram baixo índice de concordância “d”, com valores de 0,44 e 0,56, respectivamente, sendo observadas superestimativas para esses híbridos na semeadura de janeiro, indicadas pelos valores positivo de PD (\%).

Os valores de RSME abaixo de $20 \%$ permitiram inferir que a simulação para massa de um grão foi muito precisa (Tabela 6). Os maiores valores de desvio percentual foram obtidos na terceira época de semeadura com os híbridos

Tabela 1. Médias de produtividade (Prod.), número de grãos (NG) e massa de grãos (MG) em três épocas de semeadura considerando cinco híbridos de milho.

\begin{tabular}{|c|c|c|c|}
\hline Épocas de semeadura & Prod. $\left(\mathrm{kg} \mathrm{ha}^{-1}\right)$ & NG (grãos m²) & MG (mg grão-1) \\
\hline $24 / 11 / 2007$ & 6194,1 a & 2989,4 a & 210,33 a \\
\hline 19/12/2007 & 6460,8 a & 3053,3 a & 201,21 a \\
\hline $13 / 01 / 2007$ & $4160,7 \mathrm{~b}$ & 2431,1 b & $121,10 \mathrm{~b}$ \\
\hline
\end{tabular}

Médias seguidas de letras distintas nas colunas pertencem a grupos que diferem entre si pelo teste de Tukey (P < 0,05). 


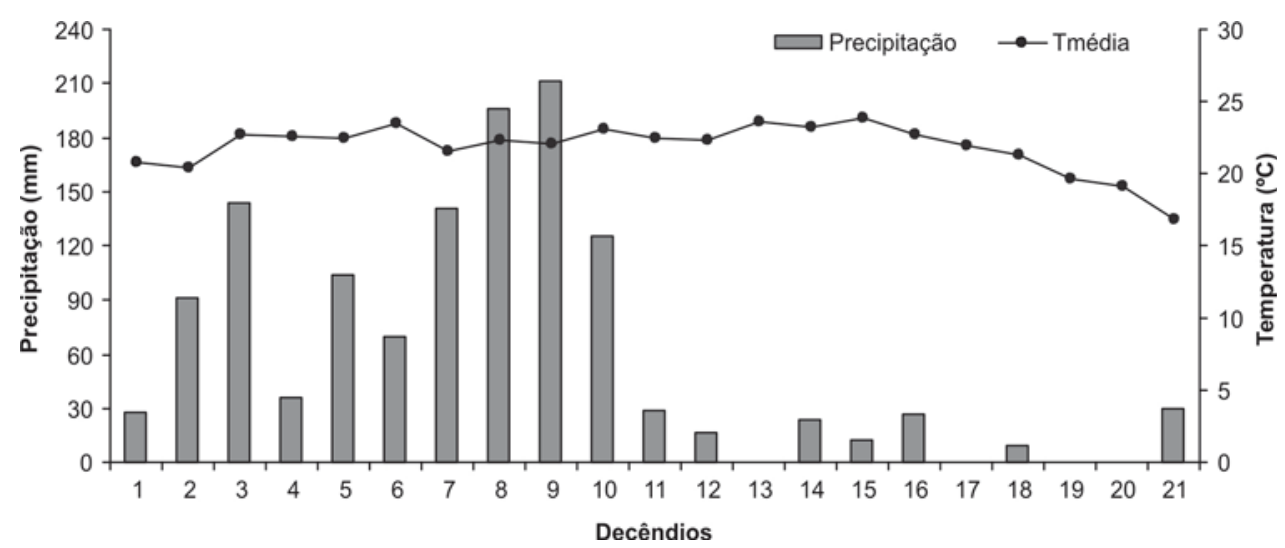

Figura 1. Dados médios de temperatura e precipitação pluvial por decêndio, em Lavras, MG, no período de 1/11/2006 a 21/05/2007. Dados obtidos no setor de Bioclimatologia da UFLA.

Tabela 2. Valores dos parâmetros obervados e calibrados, P1 (graus-dia entre a emergência das plantas e o final do estádio juvenil), P2 (coeficiente de sensitividade ao fotoperíodo), P5 (graus-dia entre o florescimento e a maturidade fisiológica), G2 (número potencial de grãos por planta) e G3 (taxa potencial de crescimento de grãos) correspondentes aos diferentes híbridos

\begin{tabular}{|c|c|c|c|c|c|c|}
\hline \multirow{2}{*}{ Híbrido } & & \multicolumn{5}{|c|}{ Parâmetros do modelo } \\
\hline & & P1 & $\mathbf{P} 2$ & P5 & G2 & G3 \\
\hline GNZ 2004 & Observado & 332 & 0,5 & 776 & 467 & 3,9 \\
\hline GNZ 2004 & Calibrado & 292 & 0,5 & 866 & 497 & 7,9 \\
\hline DKB 199 & Observado & 368 & 0,5 & 765 & 536 & 2,2 \\
\hline DKB 199 & Calibrado & 338 & 0,5 & 915 & 836 & 6,2 \\
\hline P $30 F 90$ & Observado & 345 & 0,5 & 819 & 481 & 2,9 \\
\hline P $30 F 90$ & Calibrado & 325 & 0,5 & 919 & 581 & 5,4 \\
\hline AG 7000 & Observado & 349 & 0,5 & 760 & 475 & 2,5 \\
\hline AG 7000 & Calibrado & 319 & 0,5 & 880 & 695 & 5,2 \\
\hline AG 8060 & Observado & 338 & 0,5 & 745 & 494 & 3,0 \\
\hline AG 8060 & Calibrado & 308 & 0,5 & 875 & 794 & 5,0 \\
\hline
\end{tabular}

Tabela 3. Valores médios de número de dias observados e simulados para o período entre a semeadura e o florescimento (DSF) com o modelo Ceres-Maize para cinco híbridos de milho semeados em três épocas. Índice de concordância (d), porcentagem de desvio (PD) e quadrado médio do erro (RMSE)

\begin{tabular}{|c|c|c|c|c|c|c|}
\hline \multirow{2}{*}{ Híbrido } & \multirow{2}{*}{ Data semeadura } & \multicolumn{2}{|c|}{ DSF } & \multirow{2}{*}{ PD } & \multirow{2}{*}{ RSME } & \multirow{2}{*}{ d } \\
\hline & & Observado & Simulado & & & \\
\hline \multirow{3}{*}{ AG7000 } & $24 / 11 / 2006$ & 68 & 67 & $-1,5$ & \multirow{3}{*}{1,5} & \multirow{3}{*}{0,84} \\
\hline & 19/12/2006 & 65 & 66 & 1,6 & & \\
\hline & $13 / 01 / 2007$ & 65 & 66 & 1,5 & & \\
\hline \multirow{3}{*}{ AG8060 } & 24/11/2006 & 70 & 69 & $-1,4$ & \multirow{3}{*}{1,2} & \multirow{3}{*}{0,90} \\
\hline & $19 / 12 / 2006$ & 67 & 66 & $-1,5$ & & \\
\hline & $13 / 01 / 2007$ & 68 & 68 & 0,2 & & \\
\hline \multirow{3}{*}{ P30F90 } & 24/11/2006 & 70 & 69 & $-1,4$ & \multirow{3}{*}{2,7} & \multirow{3}{*}{0,92} \\
\hline & $19 / 12 / 2006$ & 69 & 66 & $-4,3$ & & \\
\hline & $13 / 01 / 2007$ & 69 & 68 & $-1,4$ & & \\
\hline \multirow{3}{*}{ DKB199 } & $24 / 11 / 2006$ & 73 & 72 & $-1,4$ & \multirow{3}{*}{2,0} & \multirow{3}{*}{0,82} \\
\hline & $19 / 12 / 2006$ & 70 & 69 & $-1,4$ & & \\
\hline & $13 / 01 / 2007$ & 70 & 68 & $-2,8$ & & \\
\hline \multirow{3}{*}{ GNZ2004 } & $24 / 11 / 2006$ & 67 & 68 & 1,5 & \multirow{3}{*}{1,6} & \multirow{3}{*}{0,93} \\
\hline & 19/12/2006 & 63 & 64 & 1,6 & & \\
\hline & $13 / 01 / 2007$ & 63 & 64 & 1,6 & & \\
\hline
\end{tabular}

Rev. Ceres, Viçosa, v. 57, n.4, p. 486-493, jul/ago, 2010 
AG7000 e GNZ2004. Observa-se também superestimativa nos valores estimados para todos os híbridos no experimento instalado em janeiro. O índice de concordância variou entre 0,67 e 0,86 , confirmando o bom desempenho do modelo Ceres-Maize para simular a massa de grãos dos híbridos avaliados.

A produtividade de grãos foi simulada com grande precisão pelo modelo Ceres-Maize (Tabela 7).
Não houve diferença entre a produtividade de grãos dos híbridos; no entanto, observa-se que o melhor resultado da simulação foi obtido com o híbrido AG7000 com valores observados e simulados muito similares à porcentagem de desvio da estimativa, variando entre -2,3 e 4,8\%. Vale ressaltar que esse híbrido apresentou a menor variação da produtividade observada nas três épocas de semeadura e obteve o índice “d” muito elevado $(0,98)$ e com valores de RMSE me-

Tabela 4. Valores médios de número de dias observados e simulados para o período entre a semeadura e a maturidade fisiológica (DSMF) simulados com o modelo Ceres-Maize para cinco híbridos de milho semeados em três épocas, índice de concordância (d), porcentagem de desvio (PD) e quadrado médio do erro (RMSE)

\begin{tabular}{|c|c|c|c|c|c|c|}
\hline \multirow{2}{*}{ Híbrido } & \multirow{2}{*}{ Data semeadura } & \multicolumn{2}{|c|}{ DSMF } & \multirow{2}{*}{ PD } & \multirow{2}{*}{ RSME } & \multirow{2}{*}{ D } \\
\hline & & Observado & Simulado & & & \\
\hline \multirow{3}{*}{ AG7000 } & $24 / 11 / 2006$ & 122 & 122 & 0,0 & \multirow{3}{*}{2,8} & \multirow{3}{*}{0,99} \\
\hline & 19/12/2006 & 119 & 122 & 2,5 & & \\
\hline & 13/01/2007 & 125 & 120 & $-4,0$ & & \\
\hline \multirow{3}{*}{ AG8060 } & $24 / 11 / 2006$ & 125 & 125 & 0,0 & \multirow{3}{*}{4,2} & \multirow{3}{*}{0,91} \\
\hline & 19/12/2006 & 124 & 122 & $-1,6$ & & \\
\hline & $13 / 01 / 2007$ & 129 & 120 & $-7,0$ & & \\
\hline \multirow{3}{*}{ P30F90 } & 24/11/2006 & 128 & 127 & $-0,8$ & \multirow{3}{*}{6,8} & \multirow{3}{*}{0,97} \\
\hline & 19/12/2006 & 127 & 125 & $-1,6$ & & \\
\hline & 13/01/2007 & 133 & 118 & $-11,3$ & & \\
\hline \multirow{3}{*}{ DKB199 } & $24 / 11 / 2006$ & 129 & 129 & 0,0 & \multirow{3}{*}{6,2} & \multirow{3}{*}{0,80} \\
\hline & 19/12/2006 & 126 & 127 & 0,8 & & \\
\hline & 13/01/2007 & 134 & 120 & $-10,4$ & & \\
\hline \multirow{3}{*}{ GNZ2004 } & 24/11/2006 & 122 & 122 & 0,0 & \multirow{3}{*}{2,5} & \multirow{3}{*}{0,80} \\
\hline & $19 / 12 / 2006$ & 120 & 118 & $-1,7$ & & \\
\hline & $13 / 01 / 2007$ & 125 & 120 & $-4,0$ & & \\
\hline
\end{tabular}

Tabela 5. Valores médios de número grãos (NG) observados e simulados com o modelo Ceres-Maize para cinco híbridos de milho semeados em três épocas, índice de concordância (d), porcentagem de desvio (PD) e quadrado médio do erro (RMSE).

\begin{tabular}{|c|c|c|c|c|c|c|}
\hline \multirow{2}{*}{ Híbrido } & \multirow{2}{*}{ Data semeadura } & \multicolumn{2}{|c|}{ NG (grãos.m²) } & \multirow{2}{*}{ PD } & \multirow{2}{*}{ RSME } & \multirow{2}{*}{ D } \\
\hline & & Observado & Simulado & & & \\
\hline \multirow{3}{*}{ AG7000 } & $24 / 11 / 2006$ & 3030 & 3053 & 0,8 & \multirow{3}{*}{5,6} & \multirow{3}{*}{0,85} \\
\hline & 19/12/2006 & 3327 & 3585 & 7,8 & & \\
\hline & 13/01/2007 & 2996 & 2833 & $-5,5$ & & \\
\hline \multirow{3}{*}{ AG8060 } & $24 / 11 / 2006$ & 2820 & 2848 & 1,0 & \multirow{3}{*}{13,2} & \multirow{3}{*}{0,44} \\
\hline & 19/12/2006 & 2577 & 3060 & 18,7 & & \\
\hline & 13/01/2007 & 2278 & 2612 & 14,6 & & \\
\hline \multirow{3}{*}{ P30F90 } & $24 / 11 / 2006$ & 2777 & 2469 & $-1,1$ & \multirow{3}{*}{7,2} & \multirow{3}{*}{0,90} \\
\hline & 19/12/2006 & 2740 & 2726 & $-0,5$ & & \\
\hline & $13 / 01 / 2007$ & 2117 & 2034 & $-3,9$ & & \\
\hline \multirow{3}{*}{ DKB199 } & 24/11/2006 & 3370 & 2726 & $-19,1$ & \multirow{3}{*}{16,6} & \multirow{3}{*}{0,56} \\
\hline & 19/12/2006 & 3286 & 3190 & $-2,9$ & & \\
\hline & 13/01/2007 & 2104 & 2637 & 25,3 & & \\
\hline \multirow{3}{*}{ GNZ2004 } & 24/11/2006 & 2108 & 2125 & 0,8 & \multirow{3}{*}{15,2} & \multirow{3}{*}{0,75} \\
\hline & 19/12/2006 & 3009 & 2414 & $-19,8$ & & \\
\hline & 13/01/2007 & 2023 & 1820 & $-10,0$ & & \\
\hline
\end{tabular}


nores do que 5\%. Para os demais híbridos, a estimativa foi considerada boa, com RMSE menores do que $16 \%$. O menor valor de “d” $(0,80)$ foi obtido para o híbrido DKB199.

Esses resultados corroboram com os obtidos por Soler (2004) que, ao avaliar o modelo Ceres-maize na previsão de safra de milho safrinha na região de Piracicaba-SP, encontrou valores do índice de concordância (D) entre 0,84 e 0,99 e de RSME menores que $10 \%$.
A simulação proporcionou valores muito semelhantes aos observados para as datas de florescimento e maturidade fisiológica, enquanto para os componentes da produção e produtividade de grãos, principalmente na terceira época de semeadura, os valores apresentaram-se altos na maioria dos híbridos. Esses valores superestimados coincidem com os apresentados por Lima (1995), porém com valores de desviopadrão (PD) inferiores a 14\%. Hurtado et al. (2005), avalian-

Tabela 6. Valores médios de massa de um grão (MG) observado e simulado com o modelo Ceres-Maize para cinco híbridos de milho semeados em três épocas, índice de concordância (d), porcentagem de desvio (PD) e quadrado médio do erro (RMSE).

\begin{tabular}{|c|c|c|c|c|c|c|}
\hline \multirow{2}{*}{ Híbrido } & \multirow{2}{*}{ Data semeadura } & \multicolumn{2}{|c|}{ MG (mg grão $\left.{ }^{-1}\right)$} & \multirow{2}{*}{ PD } & \multirow{2}{*}{ RSME } & \multirow{2}{*}{ D } \\
\hline & & Observado & Simulado & & & \\
\hline \multirow{3}{*}{ AG7000 } & $24 / 11 / 2006$ & 206 & 195 & $-5,3$ & \multirow{3}{*}{15,7} & \multirow{3}{*}{0,71} \\
\hline & 19/12/2006 & 180 & 193 & 7,2 & & \\
\hline & $13 / 01 / 2007$ & 123 & 166 & 35,0 & & \\
\hline \multirow{3}{*}{ AG8060 } & 24/11/2006 & 208 & 206 & $-1,0$ & \multirow{3}{*}{8,6} & \multirow{3}{*}{0,89} \\
\hline & $19 / 12 / 2006$ & 220 & 199 & $-9,5$ & & \\
\hline & $13 / 01 / 2007$ & 145 & 165 & 13,8 & & \\
\hline \multirow{3}{*}{ P30F90 } & $24 / 11 / 2006$ & 208 & 230 & 10,6 & \multirow{3}{*}{13,0} & \multirow{3}{*}{0,67} \\
\hline & 19/12/2006 & 189 & 226 & 19,6 & & \\
\hline & $13 / 01 / 2007$ & 173 & 174 & 0,6 & & \\
\hline \multirow{3}{*}{ DKB199 } & $24 / 11 / 2006$ & 200 & 250 & 25,0 & \multirow{3}{*}{19,0} & \multirow{3}{*}{0,89} \\
\hline & 19/12/2006 & 239 & 250 & 4,6 & & \\
\hline & $13 / 01 / 2007$ & 163 & 190 & 16,6 & & \\
\hline \multirow{3}{*}{ GNZ2004 } & 24/11/2006 & 240 & 210 & $-12,5$ & \multirow{3}{*}{19,0} & \multirow{3}{*}{0,87} \\
\hline & 19/12/2006 & 259 & 290 & 12,0 & & \\
\hline & $13 / 01 / 2007$ & 205 & 270 & 31,7 & & \\
\hline
\end{tabular}

Tabela 7. Valores médios de produtividade de grãos (Prod.) observados e simulados com o modelo Ceres-Maize para cinco híbridos de milho semeados em três épocas, índice de concordância (d), porcentagem de desvio (PD) e quadrado médio do erro (RMSE)

\begin{tabular}{|c|c|c|c|c|c|c|}
\hline \multirow{2}{*}{ Híbrido } & \multirow{2}{*}{ Data semeadura } & \multicolumn{2}{|c|}{ Prod. (kg ha' $\left.{ }^{-1}\right)$} & \multirow{2}{*}{ PD } & \multirow{2}{*}{ RSME } & \multirow{2}{*}{ D } \\
\hline & & Observado & Simulado & & & \\
\hline \multirow{3}{*}{ AG7000 } & $24 / 11 / 2006$ & 5985 & 5954 & $-0,5$ & \multirow{3}{*}{3,3} & \multirow{3}{*}{0,98} \\
\hline & $19 / 12 / 2006$ & 6606 & 6920 & 4,8 & & \\
\hline & $13 / 01 / 2007$ & 5100 & 4983 & $-2,3$ & & \\
\hline \multirow{3}{*}{ AG8060 } & $24 / 11 / 2006$ & 5886 & 5872 & $-0,2$ & \multirow{3}{*}{12,7} & \multirow{3}{*}{0,91} \\
\hline & $19 / 12 / 2006$ & 6913 & 6098 & $-11,8$ & & \\
\hline & $13 / 01 / 2007$ & 3435 & 4301 & 25,0 & & \\
\hline \multirow{3}{*}{ P30F90 } & $24 / 11 / 2006$ & 5765 & 5663 & $-1,8$ & \multirow{3}{*}{13,0} & \multirow{3}{*}{0,83} \\
\hline & $19 / 12 / 2006$ & 5705 & 6181 & 8,3 & & \\
\hline & $13 / 01 / 2007$ & 4630 & 3526 & $-23,8$ & & \\
\hline \multirow{3}{*}{ DKB199 } & $24 / 11 / 2006$ & 6814 & 6875 & 0,8 & \multirow{3}{*}{15,7} & \multirow{3}{*}{0,80} \\
\hline & $19 / 12 / 2006$ & 6913 & 6078 & 17,7 & & \\
\hline & $13 / 01 / 2007$ & 3838 & 5188 & 35,2 & & \\
\hline \multirow{3}{*}{ GNZ2004 } & $24 / 11 / 2006$ & 6518 & 6478 & $-0,8$ & \multirow{3}{*}{14,1} & \multirow{3}{*}{0,84} \\
\hline & $19 / 12 / 2006$ & 6277 & 7108 & 13,2 & & \\
\hline & $13 / 01 / 2007$ & 4987 & 5800 & 31,0 & & \\
\hline
\end{tabular}

Rev. Ceres, Viçosa, v. 57, n.4, p. 486-493, jul/ago, 2010 
do a eficiência do Ceres-Maize na simulação da produção de grãos do híbrido A2345, encontraram valores de desvio-padrão (PD) entre 31 e 36\%, e explicaram que esses altos valores ocorrem devido à influência da variabilidade espacial dos atributos do solo na eficiência do modelo.

Os resultados obtidos neste trabalho evidenciam que o modelo simulou com boa precisão a produtividade de grãos nas três épocas, sendo os maiores erros observados no plantio de janeiro de 2007. Isso pode ser explicado devido à calibração do modelo ter sido realizada com os dados obtidos na primeira época de semeadura e também às condições ambientais durante a condução do experimento instalado em janeiro terem sido muito diferentes nos demais. Vale ressaltar que as condições ambientais não favoráveis ao bom desenvolvimento da cultura afetaram a eficiência do modelo. Além disso, a ausência de critérios para a escolha correta dos parâmetros de calibração pode ter influenciado na eficiência do modelo.

Vale destacar que o modelo Ceres-Maize foi desenvolvido e testado em condições temperadas de cultivo e com material genético adaptado a essas condições, por isso imprecisões nas simulações são esperadas nas condições tropicais brasileiras. No entanto, observou-se que o CeresMaize é boa ferramenta de auxílio à pesquisa e para previsão da produção de milho.

Este estudo evidencia a importância da realização de novas avaliações do modelo em diferentes situações, em ambientes variados que integrem situações diversificadas como o manejo da irrigação, a fertilidade de solos, as adubações, bem como a utilização de híbridos e populações de plantas diferentes visando à obtenção de estimativas mais confiáveis, de modo que essas possam permitir a generalização dos resultados para uma região mais ampla.

\section{CONCLUSÕES}

O modelo Ceres-Maize é eficiente na simulação das datas de florescimento e maturidade fisiológica dos híbridos. Ele é uma boa ferramenta para a simulação dos componentes do rendimento e da produtividade de grãos de híbridos de milho em condições favoráveis de cultivo e precisa de ajustes para sua utilização nas condições tropicais, pois o déficit hídrico afeta a eficiência desse na simulação dos componentes de rendimento e produtividade de grãos de milho.

\section{REFERENCIAS}

Bergonci JI, Bergamaschi JI, Santos AO, França S, Radin B, Dourado-Neto D, Nielsen DR, Hopmans JW, Reichardt K, Santos Bacchi OO \& Lopes PP (2001) Soil water retention curve (software): version 3.0. Piracicaba, ESALQ. CD-ROM.

Dourado-Neto D, Nielsen DR, Hopmans JW, Reichardt K, Santos Bacchi OO \& Lopes PP (2001) Soil water retention curve (software): version 3.0. Piracicaba, ESALQ. CD-ROM.
Empresa Brasileira de Pesquisa Agropecuária-EMBRAPA (2000) Sistema brasileiro de classificação de solos. Brasília, Embrapa. 412p.

Fancelli AL \& Dourado-Neto D (2000) Produção de milho. Guaíba, Agropecuária. 360p.

Ferreira DF (2000) Análises estatísticas por meio do SISVAR para Windows versão 4.0. In: 45 a Reunião Anual da Região Brasileira da Sociedade Internacional de Biometria, São Carlos. Programas e Resumos, UFSCar. p.235.

Hoeft RG (2003) Desafios para obtenção de altas produtividades de milho e soja nos EUA. Informações Agronômicas, 104:1-4.

Hoogenboom G \& White JW (2003) Improving physiological assumptions of simulation models by using gene-based approaches. Agronomy Journal, 85:82-89.

Hurtado SMC (2004) Influência da Variabilidade Espacial dos Atributos dos Solos na Simulação da Produtividade de Milho, utilizando o Ceres-Maize. Dissertação de Mestrado. Universidade Federal de Lavras, Lavras. 95p.

Hurtado SMC, Paglis CM \& Von Pinho RG (2005) Eficiência do modelo Ceres-Maize na predição da produtividade de milho em áreas com presença de variabilidade espacial. Ciência Agrotecnica, 29:1153-1160.

Jame YW \& Curtfourth HW (1996) Crop growth models for decision support systems. Canadian Journal of Plant Science, 76:9-19.

Jamieson PD, Porter JR \& Wilson DR (1991) A test of the computer simulation model ARC-WHEAT1 on wheat crops grown in New Zeland. Field Crops Research, 27:337-350.

Jones CA \& Kiniry JR (1986) Ceres-Maize: a simulation model of maize growth and development College Station. Texas, A \& M University. 194p.

Lima MGde (1995) Calibração e validação do modelo Ceres-Maize em condições tropicais do Brasil. Tese de Doutorado. Escola Superior de Agricultura de Luiz de Queiroz, Piracicaba. 108p.

Loague K \& Green RE (1991) Statistical and graphical methods for evaluating solute transport models: overview and application. Journal of Contaminant Hydrology, 7:51-73.

Salvador RJ (1993) Use of Computerized Simulation to Advance Agricultural Researc hin Developing Countries. In: $8^{\circ}$ International Congress on Research in Electrical Sciences, Torreón. Anais, Instituto Tecnológico de la Laguna. p.20-24.

Soler CT (2004) Uso do modelo Ceres-Maize para previsão de safra do milho "safrinha”. Tese de Doutorado. Escola Superior de Agricultura “Luiz de Queiroz”, São Paulo. 132p.

Willmott CJ, Akleson GS, Davis RE, Feddema JJ, Klink KM, Legates DR, Odonnell J \& Rowe CM (1985) Statistics for the evaluation and comparison of models. Journal of Geophysical Research, 90:8995-9005. 